\title{
Transcriptomic Characterization of a Chicken Embryo Model Infected With Duck Hepatitis A Virus Type 1
}

\begin{abstract}
Jinyan Xie ${ }^{1,2 t}$, Qiurui Zeng ${ }^{3 \dagger}$, Mingshu Wang ${ }^{1,2,4 t}$, Xumin Ou ${ }^{1,2 t}$, Yunchao $\mathrm{Ma}^{1,2}$, Anchun Cheng ${ }^{1,2,4 *}$, Xin-Xin Zhao ${ }^{1,2,4}$, Mafeng Liu ${ }^{1,2,4}$, Dekang Zhu ${ }^{2,4}$, Shun Chen ${ }^{1,2,4}$, Renyong Jia'1,2,4, Qiao Yang ${ }^{1,2,4}$, Ying Wu ${ }^{1,2,4}$, Shaqiu Zhang ${ }^{1,2,4}$, Yunya Liu ${ }^{1,2,4}$, Yanling Yu1,2,4, Ling Zhang ${ }^{1,2,4}$ and Xiaoyue Chen ${ }^{1,2,4}$
\end{abstract}

${ }^{1}$ Institute of Preventive Veterinary Medicine, Sichuan Agricultural University, Chengdu City, China, ${ }^{2}$ Key Laboratory of Animal Disease and Human Health of Sichuan Province, Sichuan Agricultural University, Chengdu City, China, ${ }^{3}$ School of Medicine, Shanghai Jiao Tong University, Shanghai, China, ${ }^{4}$ Avian Disease Research Center, College of Veterinary Medicine, Sichuan Agricultural University, Chengdu City, China

OPEN ACCESS

Edited by:

Fabrizio Ceciliani,

Università degli Studi

di Milano, Italy

Reviewed by:

Muhammad Zubair Shabbir, University of Veterinary and Animal Sciences, Pakistan

Meilin Jin,

Huazhong Agricultural University, China

${ }^{*}$ Correspondence: Anchun Cheng chenganchun@vip.163.com

tThese authors have contributed equally to this work.

Specialty section: This article was submitted to

Comparative Immunology, a section of the journal

Frontiers in Immunology

Received: 04 April 2018 Accepted: 26 July 2018 Published: 24 August 2018

Citation: Xie J, Zeng Q, Wang M, Ou X, Ma Y, Cheng A, Zhao X-X, Liu M, Zhu D, Chen S, Jia R, Yang $Q, W u Y$, Zhang S, Liu Y, Yu Y, Zhang L and Chen $X$ (2018) Transcriptomic Characterization of a Chicken Embryo Model Infected With Duck Hepatitis A Virus Type 1.

Front. Immunol. 9:1845. doi: 10.3389/fimmu.2018.01845
Duck hepatitis A virus type 1 (DHAV-1) is one of the most common and lethal pathogens in young ducklings. Live-attenuated DHAV vaccine ( $\mathrm{CH} 60$ strain) developed by passaging in chicken embryos provided effective immune protection for ducklings. However, the accurate mechanism for such adaption in chicken embryos is not fully revealed. Here, we utilize RNA-sequencing to perform global transcriptional analysis of DHAV-1-innoculated embryonated livers along with histopathological and ultrastructural analysis. This study revealed that infection with DHAV-1 strain $\mathrm{CH} 60$ is associated with enhanced type I and II interferon responses, activated innate immune responses, elevated levels of suppressor of cytokine signaling 1 and 3 (SOCS1 and SOCS3) accompanied with abnormalities in multiple metabolic pathways. Excessive inflammatory and innate immune responses induced by the $\mathrm{CH} 60$ strain are related to severe liver damage. Our study presents a comprehensive characterization of the transcriptome of chicken embryos infected with DHAV-CH60 and provides insight for in-depth exploration of viral adaption and virus-host interactions.

Keywords: Duck hepatitis A virus type 1, transcriptomic analysis, chicken embryo models, innate immune system, sOCS

\section{INTRODUCTION}

Duck hepatitis A virus type 1 (DHAV-1), a member of the genus Avihepatovirus with characteristics of the family Picornaviridae (1-8), was first reported in Long Island, New York in 1945. DHAV-1 poses a serious threat to the duck industry worldwide $(9,10)$. There was recently an outbreak of DHAV-1 infection in Japan, and the nucleotide sequences of outbreak PCR products exhibited 96\% identity with the HB02 strain of DHAV-1, which was isolated in China (11). Therefore, this virus may have been introduced from an epidemic area into a pest-free area. DHAV-1 is one of the most common and lethal pathogens in young ducklings and is responsible for acute hepatitis characterized by petechial and ecchymotic hemorrhages of liver surfaces $(12-14)$. Due to the need for prevention and control of this disease, many studies have focused on diagnostic methods (15-20).

Current studies on the pathogenicity of DHAV-1 have been limited to the innate immune response at the transcription level (21-24). However, the complex immunological mechanisms associated with DHAV-1 remain ill-defined, which is due to the lack of an available chicken embryo model. 
Previous studies have proposed DHAV-1 infection in mature ducks as an alternative small-animal model for viral hepatitis (21). Nonetheless, there are limitations associated with duck models, such as the lack of duck-derived antibodies and the lack of stable animal sources.

The chicken embryo model is commonly used to investigate vertebrate biology (25), and several studies have utilized this animal model to explore complex mechanisms in recent years (26-29). Our lab has previously cultivated a chicken embryoattenuated strain of DHAV-1 that causes liver disease in ducks in a manner similar to DHAV-1 (30). Herein, we describe the first global transcriptional study of the liver in a specific-pathogenfree (SPF) chicken embryo model of DHAV-1 infection. The study was undertaken to explore virus-host interactions in detail and provide insight into an alternative small-animal model.

\section{MATERIALS AND METHODS}

\section{Ethics Statement}

The study was approved by the Committee of Experiment Operational Guidelines and Animal Welfare of Sichuan Agricultural University (the approved permit number is XF2014-18). Experiments were conducted in accordance with approved guidelines.

\section{Viruses and Animals}

The virulent DHAV-1 CH strain and the attenuated DHAV-1 CH60 strain were provided by the Institute of Preventive Veterinary Medicine, Sichuan Agricultural University. SPF embryonated eggs were infected with the $\mathrm{CH}$ strain at a concentration of $10^{7.88}$ copies $/ \mathrm{ml}$ and the $\mathrm{CH} 60$ strain at a concentration of $10^{7.65}$ copies $/ \mathrm{ml}$ via the allantoic cavity. Viral copies were determined by quantitative reverse transcription-polymerase chain reaction (qRT-PCR) (16).

Specific-pathogen-free embryonated eggs were purchased from Beijing Merial Vital Laboratory Animal Technology Co., Ltd. All eggs were incubated at $37.8^{\circ} \mathrm{C}$ in the same incubator and candled daily.

\section{Experimental Procedures}

Twelve-day-old embryonated eggs were randomly divided into three groups (15 embryonated eggs in each group). The embryonated eggs in the first group ( $\mathrm{CH}$ group) received $0.12 \mathrm{ml}$ of the DHAV-CH strain $\left(10^{7.88}\right.$ copies $\left./ \mathrm{ml}\right)$ via allantoic cavity inoculation, the embryonated eggs in the second group (CH60 group) received $0.20 \mathrm{ml}$ of the DHAV-CH60 strain (10.65 copies $/ \mathrm{ml}$ ) via allantoic cavity inoculation, and the final group (mock group) was inoculated with $0.20 \mathrm{ml}$ of $0.75 \%$ physiological normal saline as a negative control. Three embryonated egg livers were collected from each group at 12,24 , and $36 \mathrm{~h}$ post infection (hpi), and six embryonated eggs livers were collected from each group at $48 \mathrm{hpi}$. The right lobes of the liver specimens were immediately cryopreserved in liquid nitrogen until RNA isolation was performed. Additionally, the left lobes of the liver specimens were split into two components: one was soaked in
$4 \%$ paraformaldehyde solution for histopathological examination, and the other was soaked in $2.5 \%$ glutaraldehyde solution for electron microscopy.

\section{Hematoxylin and Eosin (HE) Staining, TUNEL Assay, and Electron Microscopy}

The livers soaked in $4 \%$ paraformaldehyde solution were dehydrated, embedded in paraffin, cut into 4 - $\mu \mathrm{m}$-thick sections, and stained with HE using standard procedures (31).

Four-micron sections from the $\mathrm{CH} 60, \mathrm{CH}$ and mock group at 48 hpi were also used to perform terminal dUTP nick end labeling (TUNEL) using an In Situ Apoptosis Detection Kit (Boster Inc., Wuhan, China) according to the manufacturer's instructions. Apoptotic cells were observed under a light microscope. The apoptotic nuclei were counted in four randomly selected nonoverlapping fields.

The livers from the $\mathrm{CH} 60, \mathrm{CH}$, and mock groups obtained at 48 hpi were post-fixed in $1.0 \%$ osmium tetroxide. After a stepwise dehydration in acetone, samples were embedded in epoxy resin 618 and polymerized at $80^{\circ} \mathrm{C}$ for $72 \mathrm{~h}$. Then, 50 -nm ultra-thin sections were prepared, collected on grids, and stained with uranyl acetate and lead citrate for subsequent examination with a Tecnai G2 F20 transmission electron microscope.

\section{RNA Isolation, cDNA Library Construction, and RNA Sequencing}

Total RNA from the livers collected at $48 \mathrm{hpi}$ was extracted using a mirVana miRNA Isolation Kit (Ambion) following the manufacturer's protocol. There were three biological replicates for each group, with each replicate comprising pooled RNA from two embryonated eggs. RNA integrity was evaluated using an Agilent 2100 bioanalyzer (Agilent Technologies, Santa Clara, CA, USA). Samples with RNA integrity numbers (RINs) $>7$ were subjected to subsequent analysis. Libraries were constructed using a TruSeq Stranded mRNA LT Sample Prep Kit (Illumina, San Diego, CA, USA) according to the manufacturer's instructions. Then, these libraries were sequenced on an Illumina sequencing platform (HiSeqTM 2500 or Illumina HiSeq X 10), and 125/150-bp paired-end reads were generated.

\section{Quantitative RT-PCR}

Gene expression levels were determined by performing qPCR using a $\mathrm{SYBR}^{\circledR}$ Premix Ex $\mathrm{Taq}^{\mathrm{TM}}$ II (Tli RNaseH Plus) Kit (TaKaRa) and an Applied CFX96 real-time PCR detection system (Bio-Rad, Hercules, CA, USA). Primer sequences were specifically designed for suppressor of cytokine signaling 1 (SOCS-1), SOCS-3, STAT1, STAT3, IRF-1, IRF-7, IFN- $\alpha, I F N-\beta, I F N-\gamma, I L-6$, IL-10, TLR3, TLR7, and GAPDH using Primer Premier 5 (Table S1 in Supplementary Material). Amplification was performed in $10-\mu \mathrm{l}$ reactions containing $0.4 \mu \mathrm{l}$ of each primer and $1 \mu \mathrm{l}$ of cDNA. The following thermal cycling conditions were used: initial activation at $95^{\circ} \mathrm{C}$ for $30 \mathrm{~s}, 40$ cycles of denaturation at $95^{\circ} \mathrm{C}$ for $5 \mathrm{~s}$, and annealing and extension at $58.6^{\circ} \mathrm{C}$ for $30 \mathrm{~s}$, and a dissociation curve analysis step. Fold change was determined using the $2^{-\Delta \Delta \mathrm{Ct}}$ method (32). 


\section{Analysis of Differentially Expressed Genes (DEGs), Cluster Analysis, and Gene Ontology (GO) and KEGG Enrichment}

FPKM (33) and read count values of each transcript (protein coding) were calculated using Bowtie 2 (34) and eXpress (35). DEGs were identified using the DESeq (36) (2012) functions estimateSizeFactors and nbinomTest. $P$-value $<0.05$ and fold change $>2$ or fold change $<0.5$ were set as the thresholds for significant differential expression. Hierarchical cluster analysis of the DEGs was performed to explore the transcript expression pattern. GO enrichment and KEGG (37) pathway enrichment analysis of the DEGs were performed using the hypergeometric distribution test with the Phyper function in the R software package. Significantly-enriched unigenes were selected based on a $q$-value of 0.05 (adjusted $p$-values were found using an optimized FDR). The distribution of unigenes within each GO/pathway category was determined by mapping all differentially expressed unigenes to terms in the GO and KEGG databases.

\section{Methylation-Specific PCR (MS-PCR)}

SOCS3 gene methylation status in the livers of the mock, $\mathrm{CH}$, and $\mathrm{CH} 60$ groups was analyzed by MS-PCR with DNA treated with an EZ DNA Methylation-Lightning ${ }^{\mathrm{TM}}$ Kit (Zymo Research, Orange, CA, USA) according to the manufacturer's instructions. The primers for the methylated sequences were FM-SOCS3 (5'-TGTTAACGGGTATTTGGATTTTTAC- $\left.3^{\prime}\right)$ and RM-SOCS3 (5'-CCTAACACTCCTCTACTTACACGAA-3'), and the primers for the unmethylated sequences were FU-SOCS3 (5'-TTAATGGGTATTTGGATTTTTATGA-3') and RU-SOCS3 (5'-TCCCTAACACTCCTCTACTTACACAA- $\left.3^{\prime}\right)$. PCR was performed in a total volume of $10 \mu$, containing $5 \mu$ l of $2 \times$ TSINGKE Master Mix, $0.3 \mu \mathrm{l}$ of each primer, and $0.5 \mu \mathrm{l}$ of treated DNA. Cycling conditions were as follows: the reaction was hot-started at $95^{\circ} \mathrm{C}$ for $5 \mathrm{~min}$, followed by 32 cycles of denaturation at $95^{\circ} \mathrm{C}$ for $60 \mathrm{~s}$, annealing at $55^{\circ} \mathrm{C}$ for $30 \mathrm{~s}$, and extension at $72^{\circ} \mathrm{C}$ for $30 \mathrm{~s}$; then, a final extension was performed at $72^{\circ} \mathrm{C}$ for $7 \mathrm{~min}$. Ten microliters of the PCR product was electrophoresed on a $1.5 \%$ agarose gel stained with ethidium bromide and imaged under UV light. Normal liver tissue DNA treated with SssI methylase and modified with sodium bisulfite according to the manufacturer's instructions (New England Biolabs, Beverly, MA, USA) was used as a positive control, and $\mathrm{ddH}_{2} \mathrm{O}$ was used as a negative control.

\section{RESULTS}

\section{Gross Lesions and Histopathological Analysis}

Embryonated eggs were collected at 12, 24, 36, and $48 \mathrm{hpi}$, and we found that the gross lesions of the CH60-infected embryos underwent dynamic changes and peaked at $48 \mathrm{hpi}$, exhibiting obvious hemorrhage and swelling (Figure 1-A12). However, none of the $\mathrm{CH}$-infected embryonated eggs exhibited gross lesions. Then, liver sections were collected and soaked in $4 \%$ paraformaldehyde solution for histopathological examination. We observed ecchymotic hemorrhage in the livers of

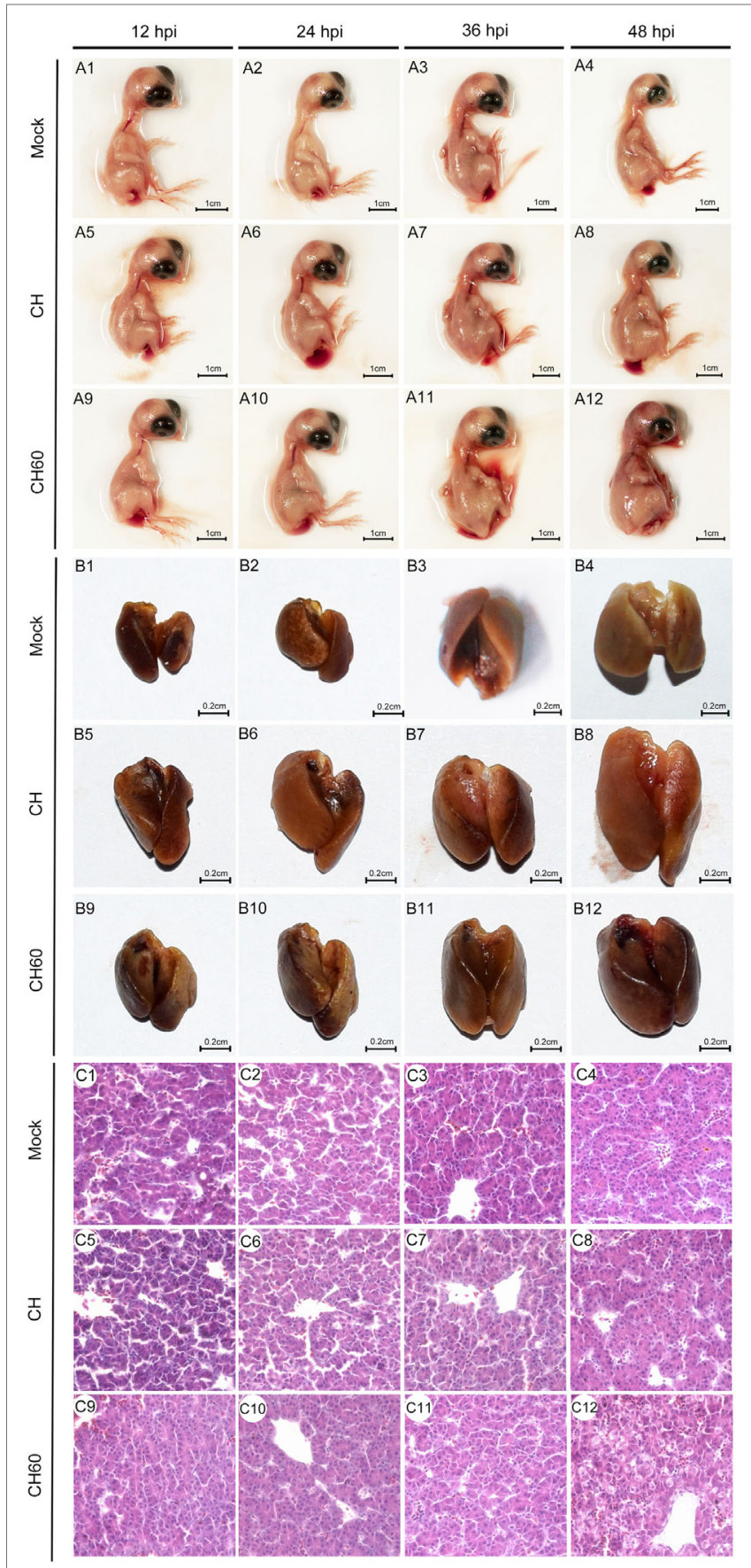

FIGURE 1 | Gross lesions and histopathological lesions in $\mathrm{CH}$ - or $\mathrm{CH} 60$ infected livers of embryonated eggs. Embryonated eggs were infected with the $\mathrm{CH}$ or $\mathrm{CH} 60$ strain, and then the livers were collected and soaked in $4 \%$ paraformaldehyde solution at 12, 24, 36, and 48 hpi. Microscopic lesions were observed under an optical microscope; magnification, 600x.

CH60-infected embryonated eggs at 48 hpi (Figure 1-B12), which corresponded to histopathological lesions. We observed infiltration of the hepatic sinusoids by large numbers of red blood cells, which was accompanied by disordered hepatic cords in the livers of $\mathrm{CH} 60$-infected embryonated eggs at 
48 hpi. Additionally, parts of the cell nuclei underwent pyknosis, karyolysis, or karyorrhexis (Figure 1-C12). For further histopathological analysis, we used electron microscopy to observe the livers of $\mathrm{CH} 60$-infected embryonated eggs at $48 \mathrm{hpi}$.

\section{Electron Microscopy and Apoptotic Analysis}

Transmission electron microscopy (TEM) analysis of the embryonated egg liver tissue samples from the mock, $\mathrm{CH}$, and $\mathrm{CH} 60$ groups at 48 hpi is shown in Figure 2. TEM images of the mock group showed clear nuclear structures and mitochondria in the hepatocytes (Figure 2A1,A2), and hepatic sinus endothelial cells were detected in the mock group (Figure 2A3,A4). There were no obvious differences in the nuclear and mitochondrial structures of the mock and $\mathrm{CH}$ groups (Figure 2B1); however, hepatic lipoid drops and autophagic vesicles were detected in the hepatocytes of the $\mathrm{CH}$ group (Figure 2B4). Compared to the mock and $\mathrm{CH} 60$ groups, hepatocytes in the $\mathrm{CH}$ group showed the accumulation of large amounts of glycogen (Figure 2B3,B4). TEM images of the CH60 group exhibited obvious pathologic changes, including the exit of large numbers of lipoid drops from the hepatocytes, expansion of the rough endoplasmic reticulum (Figure $2 \mathrm{C} 2$, blue arrow), and swelling of the mitochondria where the ridge was fractured (Figure 2C2, black arrow). Moreover, there were abundant secondary lysosomes (Figure 2C3,C4,D3,D4, red arrow) and lysosomal residues (Figure 2D2, green arrow), and organelles such as mitochondria were autophagocytosed (Figure 2C1, yellow arrow).

Then, we also stained the same liver tissue to detect TUNEL and counted the number of apoptotic nuclei. We observed obvious differences in apoptosis between the $\mathrm{CH} 60$ and mock groups ( $p=0.011$, Figure 3B); interestingly, most of the apoptotic cells were detected in the hepatic sinusoids (Figure 3A).

\section{Transcriptional Profiling of SPF Embryonated Eggs Infected With the DHAV-1 CH or CH60 Strain}

We performed transcriptional profiling of $\mathrm{CH} 60$-infected livers using the most severe lesions. Total RNA from the livers (48 hpi) of $\mathrm{CH}$ - or $\mathrm{CH} 60$-infected embryonated eggs and from the livers of mock-infected embryonated eggs was analyzed by RNA-Seq. Three biological replicates, each comprising pooled RNA from two embryonated eggs, were sequenced using three lanes of the

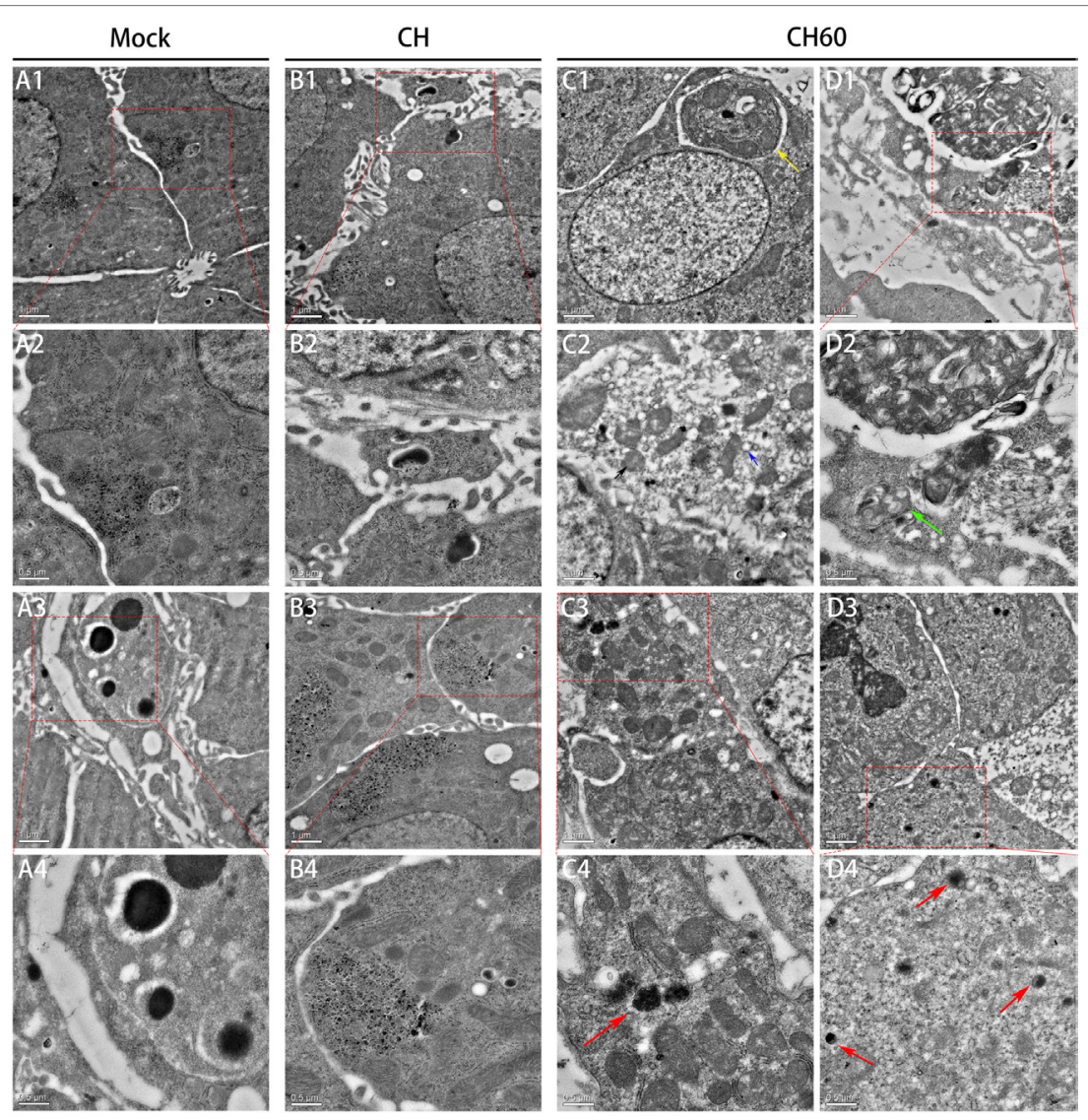

FIGURE 2 | Transmission electron microscopy analysis of liver tissue of the mock, $\mathrm{CH}$ and $\mathrm{CH} 60$ groups at 48 hpi. A: mock group; A2 and A4 are magnifications of the red boxes in $\mathrm{A} 1$ and $\mathrm{A} 3$, respectively. B: $\mathrm{CH}$ group. B2 and B4 are magnifications of the red boxes in B1 and B3, respectively. C and D: $\mathrm{CH} 60$ group. $\mathrm{C} 4$, D2, and D4 are magnifications of the red boxes in C3, D1, and D3, respectively. 

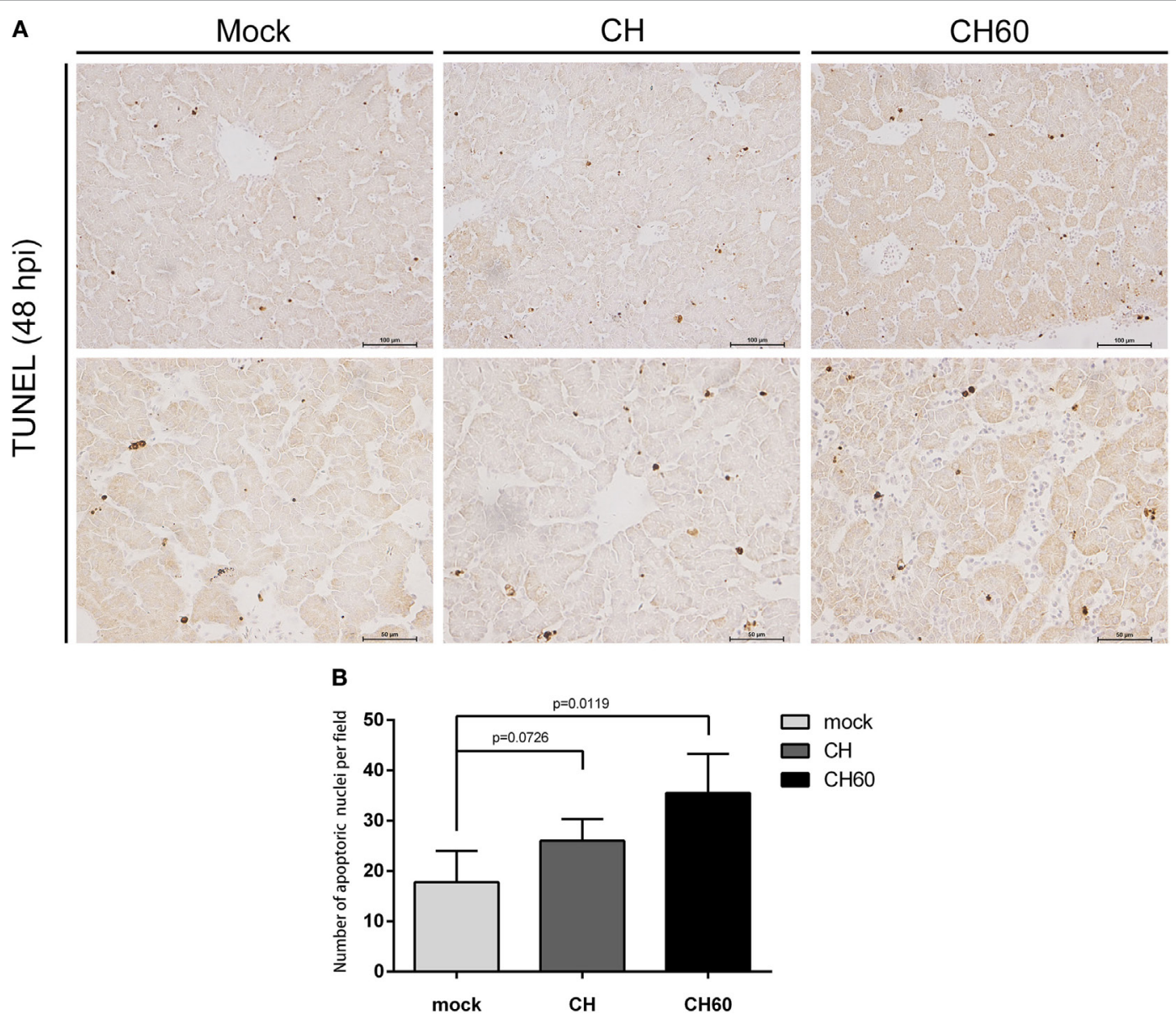

FIGURE 3 | TUNEL assay of the livers of $\mathrm{CH}$ - or $\mathrm{CH} 60$-inoculated embryonated eggs at $48 \mathrm{hpi}$. (A) TUNEL staining of the livers of the mock, $\mathrm{CH}$, and $\mathrm{CH} 60$ groups at 48 hpi. (B) Number of apoptotic nuclei identified by TUNEL staining. Student's $t$-test was used for statistical analysis to compare the mock and treated groups.

Illumina HiSeq 2000 platform. Quality control analyses and read alignment data are shown in Figure S2 in Supplementary Material. DESeq Software was used to identify DEGs in the different infected livers. The list of DEGs $(q<0.01$ and fold change $>4)$ and the up- and downregulated genes are provided in Table S2 in Supplementary Material.

\section{Differential Gene Expression Analysis}

We analyzed the DEGs among the mock, $\mathrm{CH}$, and $\mathrm{CH} 60$ groups with DESeq2. Compared with the mock group, the $\mathrm{CH}$ and CH60 groups contained 150 and 2,336 DEGs, respectively ( $p$-value $<0.05$ and fold change $>2$ ). In addition, there were 2,191 DEGs between the CH60 and CH groups, 1,732 of which were shared between the $\mathrm{CH} 60$ and mock groups (Table 1). To further analyze the DEGs, we selected more stringent filter conditions ( $p$-value $<0.01$ and fold change $>4$ ). Following comparison with the mock and $\mathrm{CH}$ groups, there were 844 and 718 DEGs in the CH60 group, respectively. These results were clearly visualized by clustering the samples by differential treatment and by constructing a volcano plot of the DEGs (Figure 4).
TABLE 1 | Number of differentially expressed genes between comparisons*.

\begin{tabular}{|c|c|c|c|c|c|}
\hline \multicolumn{3}{|c|}{ Individual comparisons } & \multicolumn{3}{|c|}{$\begin{array}{c}\text { Overlapping genes } \\
\text { between comparisons }\end{array}$} \\
\hline Comparison & $\begin{array}{c}p-\text { Value }<0.05 \\
\text { FC }>2\end{array}$ & $\begin{array}{c}p-\text { Value }<0.01 \\
\text { FC }>4\end{array}$ & $\begin{array}{l}\text { Mock vs } \\
\text { CH }\end{array}$ & $\begin{array}{l}\text { Mock vs } \\
\text { CH60 }\end{array}$ & $\begin{array}{l}\text { CH vs } \\
\mathrm{CH} 60\end{array}$ \\
\hline Mock vs $\mathrm{CH}$ & 150 & 10 & - & 72 & 73 \\
\hline Mock vs $\mathrm{CH} 60$ & 2,336 & 844 & 24 & - & 1,732 \\
\hline $\mathrm{CH}$ vs $\mathrm{CH} 60$ & 2,191 & 718 & 20 & 603 & - \\
\hline
\end{tabular}

*Number above "-" indicates DEG at p-value $<0.05$ and fold change $>2$ between indicated comparisons. Number below "-" indicates DEG at $p$-value $<0.01$ and fold change $>4$ between indicated comparisons.

\section{DHAV-1-Mediated Changes in Expression}

There was a clear difference in the number of DEGs between the $\mathrm{CH}$ and $\mathrm{CH} 60$ groups compared with the mock group (the $\mathrm{CH}$ group had 150 DEGs, and the $\mathrm{CH} 60$ group had 2,336 DEGs; $p$-value $<0.05$ and fold change $>2$ ). These DEGs reflected the differential responses of the host to these two different virulent viruses. Therefore, we performed GO analysis and KEGG pathway analysis to filter the biological processes and pathways 
A

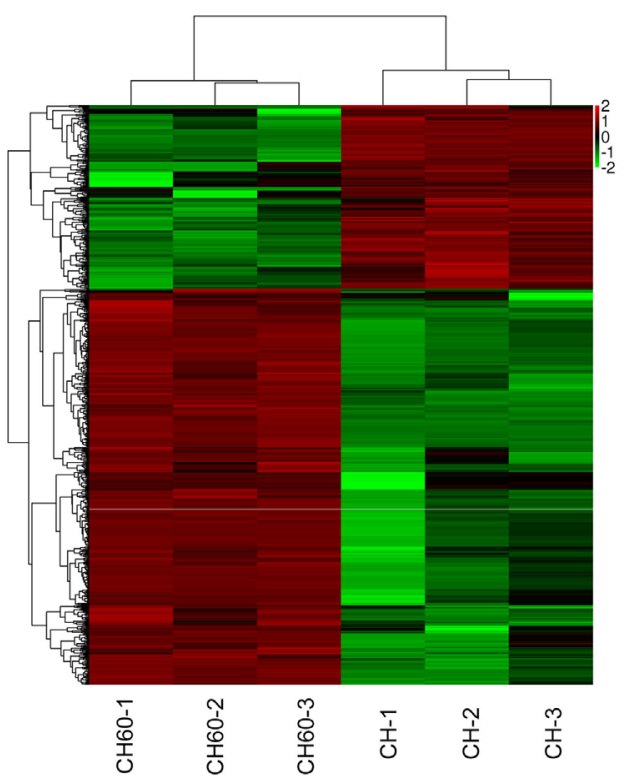

C

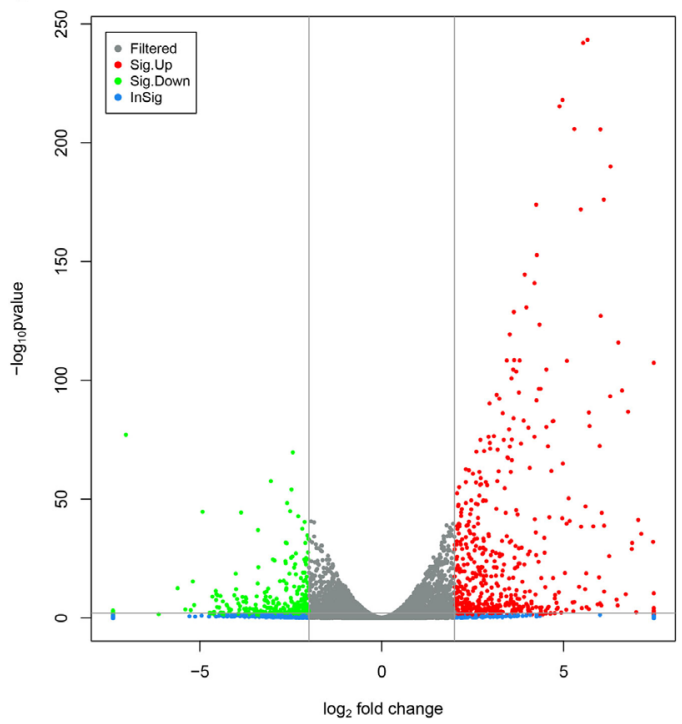

B

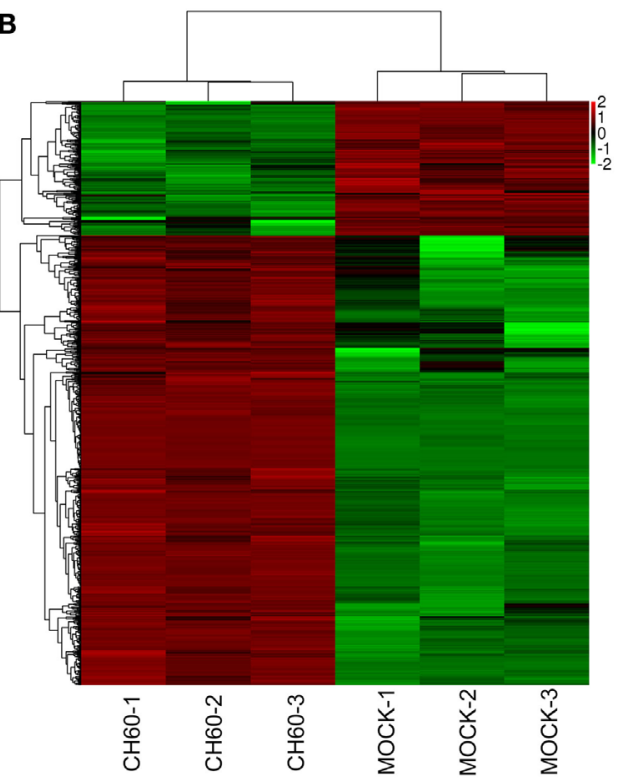

D

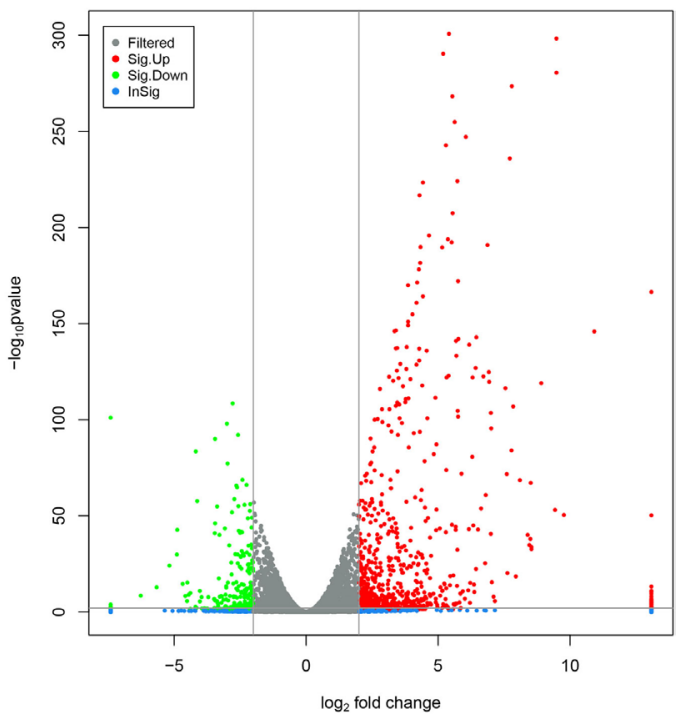

FIGURE 4 | Analysis of differentially expressed genes (DEGs) of the mock, $\mathrm{CH}$, and $\mathrm{CH} 60$ groups ( $D$-value $<0.01$ and fold change $>4$ ). A heatmap was used to classify the gene expression patterns, and a volcano plot displayed the number of DEGs. (A,B) The $x$-axis represents the experimental conditions. (C) Volcano plot of DEGs between the $\mathrm{CH}$ and $\mathrm{CH} 60$ groups. (D) Volcano plot of DEGs between the MOCK and CH60 groups. The $y$-axis indicates the negative logarithm of the $p$-value; the $x$-axis indicates the base 2 logarithm of fold change.

impacted by DHAV-1. When comparing the $\mathrm{CH}$ group to the mock group, 150 genes were observed to be significantly differentially expressed ( $p$-value $<0.05$ and fold change $>2$ ), and most of these genes are involved in interactions between neuroactive ligands and receptors, such as CHRNA4, GABRB2, GRIA4, GRM7, and OPRM1 (Figure S4B in Supplementary Material). However, comparison of the $\mathrm{CH} 60$ and mock groups yielded 844 DEGs ( $p$-value $<0.01$ and fold change $>4$ ) involved in multiple biological processes and pathways.

Gene ontology enrichment indicated that multiple vital biological processes are involved in CH60 strain infection (Figure 5A), including inflammatory response, cytokine-mediated signaling pathway, defense response to virus, cellular response to interferon gamma, and immune response. By tracking the genes involved in these biological processes, we found ILIO (FC = 371.6) and IL18 ( FC $=8.8)$ to be significantly upregulated in the inflammatory response. SOCS1 $(\mathrm{FC}=45.8), \operatorname{SOCS} 3(\mathrm{FC}=117.6)$, and IFN- $\beta(\mathrm{FC}=\mathrm{INF})$ participate in the cytokine-mediated signaling pathway; and IL6 (FC = INF), OASL (FC = 1,526.6), IFIT5 $(\mathrm{FC}=1,558.6), T L R 3(\mathrm{FC}=11.3)$, and $\operatorname{IRF} 1(\mathrm{FC}=46.9)$ are involved in the defense response to virus. Additionally, IFN- $\gamma$ might play a crucial role in DHAV-1 CH60 infection. Four key chemokines, CCL4 (FC = 372.7), CCL19 (FC = 128.5), CCL26 $(\mathrm{FC}=18.9)$, and $C X 3 C L 1(\mathrm{FC}=20.5)$, participate in the cellular 


\section{A Mock vs $\mathrm{CH} 60$}
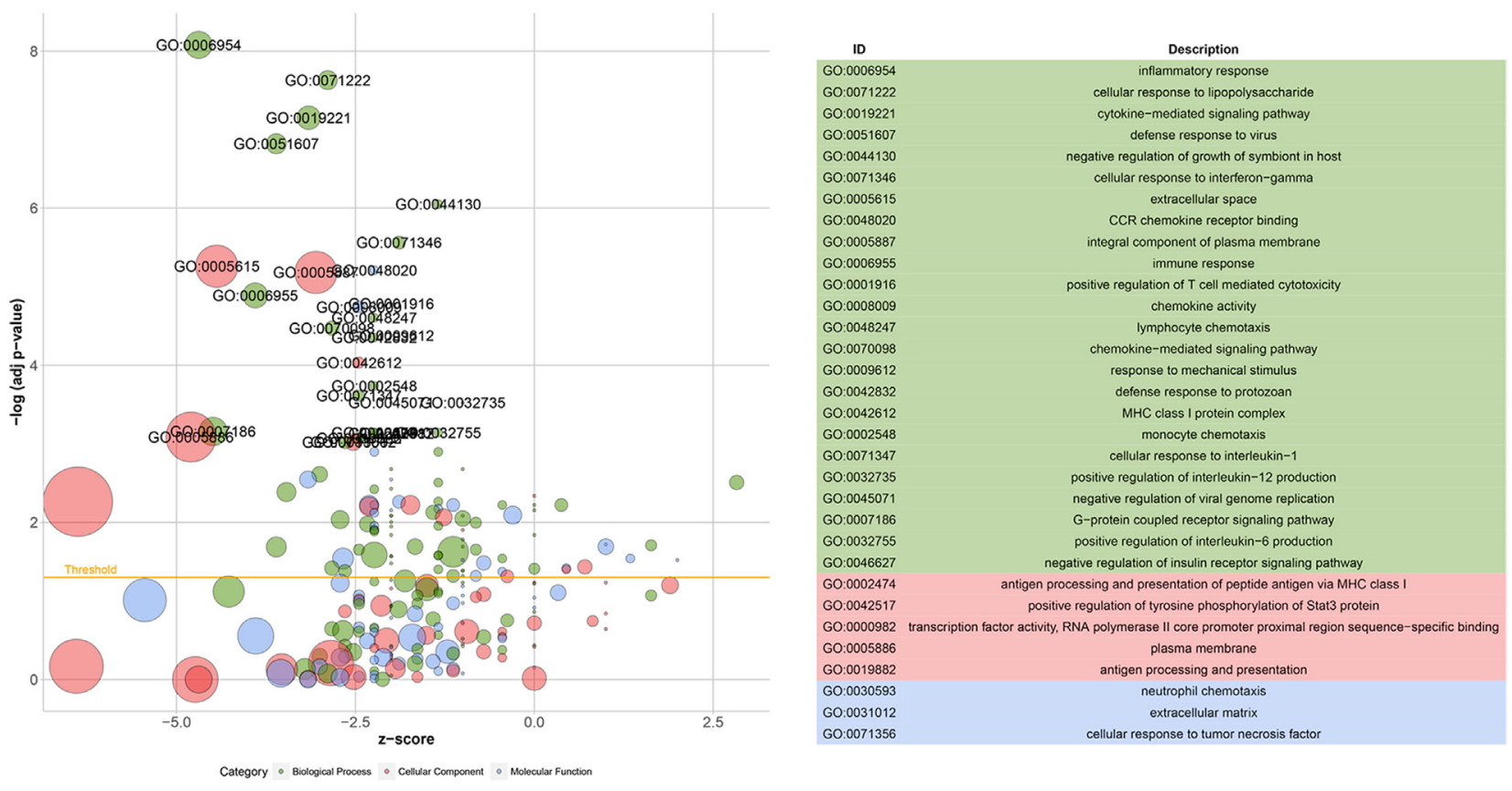

\section{B $\mathrm{CH}$ vs $\mathrm{CH} 60$}
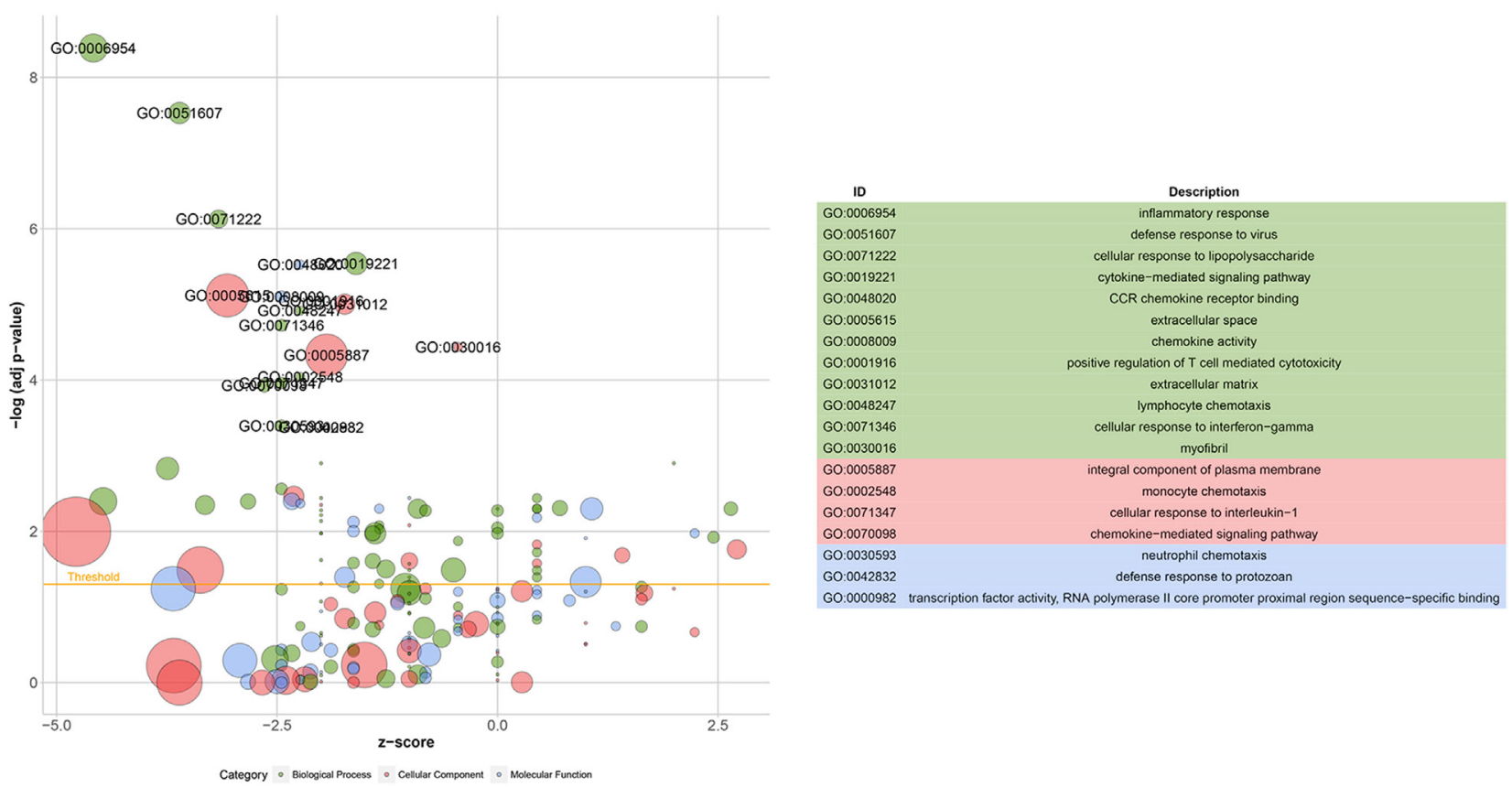

FIGURE 5 | Gene ontology (GO) enrichment analysis of differentially expressed genes (DEGs). The $z$-score is assigned to the $x$-axis, and the negative logarithm of the adjusted $p$-value is assigned to the $y$-axis. The areas of the displayed circles are proportional to the number of genes assigned to the term, and the colors correspond to the categories. (A) GO enrichment analysis of DEGs between the mock group and $\mathrm{CH} 60$ group (p-value < 0.01 and fold change $>4$ ). (B) GO enrichment analysis of DEGs between the $\mathrm{CH}$ group and $\mathrm{CH} 60$ group ( $p$-value $<0.01$ and fold change $>4$ ).

response to IFN- $\gamma$ (Table S3 in Supplementary Material). Among the abovementioned biological processes, defense response to virus was the only common biological process during $\mathrm{CH}$ strain infection (Figure S4A in Supplementary Material). Furthermore, by analyzing $\mathrm{GO}$ enrichment of DEGs between the $\mathrm{CH}$ group and the $\mathrm{CH} 60$ group, we found that the identified biological 
processes almost completely overlapped with those identified by GO enrichment of DEGs between the mock group and the CH60 group (Figure 5B).

Three pattern recognition receptor signaling pathways of the innate immune system were activated by $\mathrm{CH} 60$ infection, namely, the toll-like receptor signaling pathway (TLR3, MYD88, IKKE, $I R F 7$, and $M D-2$ ), the retinoic acid-inducible gene I (RIG-I)-like receptor signaling pathway (MDA5, LGP2, TRIM25, and STING), and the nucleotide oligomerization domain (NOD)-like receptor signaling pathway (RIPK2, Caspase1, and TNFAIP3); another key signaling pathway, the JAK-STAT signaling pathway (SOCS1, SOCS3, STAT1, STAT2, and STAT4), was also involved (Figure 6).

Duck hepatitis A virus type $1 \mathrm{CH} 60$ infection led to abnormalities in multiple metabolic pathways in the liver (Figure 6).
For example, in tryptophan metabolism (Figure S5A in Supplementary Material), the expression of tryptophan hydroxylase $1(T P H 1, F C=61)$ and tryptophan 2,3-dioxygenase (TDO2, $\mathrm{FC}=4.2$ ) was upregulated, potentially affecting tryptophan biosynthesis after $\mathrm{CH} 60$ infection. In terms of fatty acid biosynthesis (Figure S5B in Supplementary Material), we found that expression of the key protein fatty acid synthase (FASN) was 10 -fold higher after $\mathrm{CH} 60$ infection, potentially stimulating fatty acid synthesis. This finding was consistent with the observation of large numbers of fat particles by TEM. In addition, we were interested in a vacuolar ATPase, ATP6V1G3 $(\mathrm{FC}=873)$, in the phagosome membrane (Figure S5C in Supplementary Material), which played an important role in the evolution of the phagosome (38), consistent with observations of the phagosome by TEM.

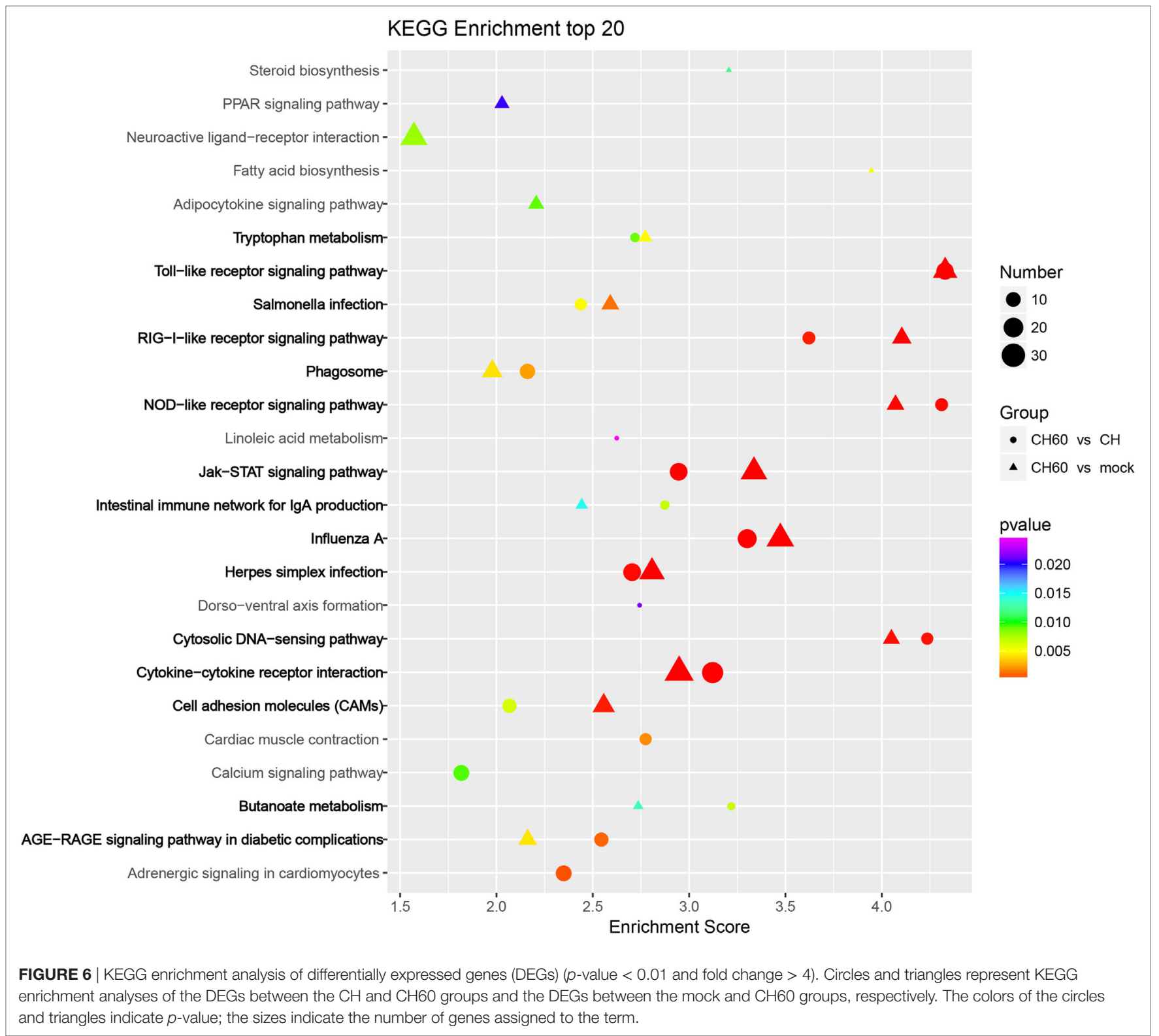




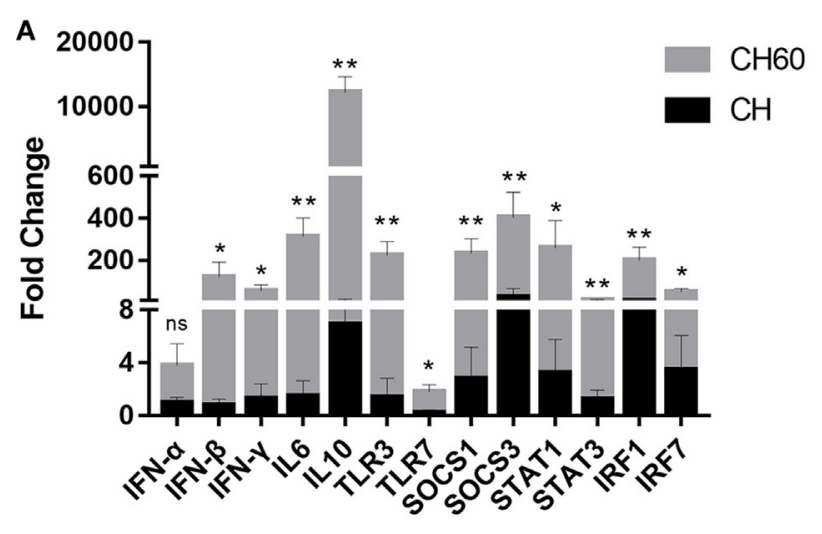

B

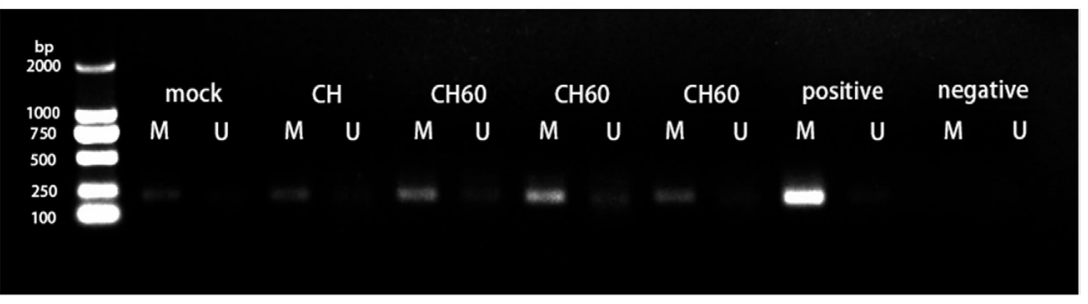

FIGURE 7 | Confirmation of differentially expressed genes by RT-PCR and methylation status of SOCS3. (A) Gene expression levels were measured by the $2^{-\Delta \Delta C t}$ method with relative quantification. Differences in the expression levels of the various genes between strains $\mathrm{CH}$ and $\mathrm{CH} 60$ were analyzed using Student's $t$-test and were considered significant as follows: ${ }^{*} p<0.05$; ${ }^{* *} p<0.01$; (B) Methylation status of the SOCS3 gene in liver tissues from Duck hepatitis A virus type 1 (DHAV-1)-infected embryonated eggs. DNA from the liver tissues of embryonated eggs infected with DHAV-1 at 48 hpi was subjected to methylation-specific PCR. M, methylation-specific primers; U, non-methylation-specific primers.

\section{Confirmation of Differential Gene Expression and Methylation Status of SOCS3}

We confirmed expression of 13 critical DEGs, namely, SOCS-1, SOCS-3, STAT1, STAT3, IRF-1, IRF-7, IFN- $\alpha, I F N-\beta, I F N-\gamma$, $I L-6, I L-10, T L R 3$, and TLR7, by qRT-PCR in the same samples. Compared to the $\mathrm{CH}$ group, gene expression was significantly higher in the CH60 group (Figure 7A). Importantly, the genes identified by qRT-PCR exhibited similar expression levels as those detected via transcriptomic analysis. Furthermore, we determined the methylation status of SOCS3 in the livers of the mock, $\mathrm{CH}$, and $\mathrm{CH} 60$ groups. All samples showed SOCS3 hypermethylation (Figure 7B).

\section{DISCUSSION}

Herein, we describe the first global intrahepatic transcriptional profiles of embryonated eggs infected with the virulent DHAV-1 $\mathrm{CH}$ strain or the attenuated $\mathrm{CH} 60$ commercial vaccine strain and combined the results with microstructural and ultrastructural analyses to compare the effects of the two strains. Notably, the hepatic sinusoids were infiltrated by large numbers of red blood cells, which was accompanied by disordered hepatic cords and granular degeneration in the livers of $\mathrm{CH} 60$-infected embryonated eggs, consistent with liver injury in duck embryos infected with DHAV-1 (21). We also observed abundant lysosomes and secondary lysosomes in TEM images of the CH60 group
(Figure 2). A similar hepatotropic virus, hepatitis A virus, utilized lysosomal organelles to facilitate nonlytic viral release, and final maturation was catalyzed by lysosomal proteases (39). Therefore, we hypothesized that a similar phenomenon occurred in the livers of DHAV-1-infected embryonated eggs. Moreover, the mitochondria in the livers of the $\mathrm{CH} 60$ group were slightly swollen where the ridge was fractured (Figure 2), which was consistent with mitochondrial injury in ducks infected with DHAV-1 (40). The mitochondrial apoptosis pathway is the main pathway of apoptosis, and damaged mitochondria are likely to affect apoptosis $(41,42)$. There was obvious apoptosis in the livers of CH60-infected embryonated eggs. Notably, several apoptotic cells clung to hepatocytes, and we speculate that these cells might be apoptotic hepatic stellate cells. The current study revealed that the liver can repair fibrosis by inducing the apoptosis of hepatic stellate cells $(43,44)$.

The fundamental role of the innate immune system is to detect invading viruses, induce inflammatory responses, produce cytokines, and chemokines to fight against viral infection, and most importantly, activate adaptive immunity $(45,46)$. Invading viruses are detected by pattern-recognition receptors (PRRs), which include toll-like receptors, RIG-I-like receptors, and NODlike receptors. We found that the $\mathrm{CH} 60$ strain could be detected by multiple PRRs, especially TLR3 and TLR7. Once TLR3 and TLR7 sense viral RNA, downstream molecules (IRF3 and IRF7) are activated, resulting in induction of type I IFN, including IFN- $\alpha$ and IFN- $\beta$. This mechanism corresponds with our results (Figure 7). The inflammatory response is a double-edged 
sword that plays an important role in liver metabolism. A mild inflammatory response exerts consistent hepatoprotective effects. Conversely, excessive inflammation may cause liver damage (47). Previous studies have indicated that DHAV-1 induces excessive inflammatory responses and causes tissue damage in the liver $(21,48)$ and kidney (1). In our study, a pro-inflammatory mediator $(I L-6)$ and an anti-inflammatory mediator $(I L-10)$ were significantly upregulated during $\mathrm{CH} 60$ infection, combined with severe pathological damage. Inflammation is known to be driven by apoptosis in the liver (49). Apoptosis was visibly induced by the CH60 strain. Therefore, we hypothesized that CH60 infection induced apoptosis in the liver, that hepatocyte apoptosis drove inflammation in the liver, and that excessive inflammatory responses caused liver damage. To directly attack invading viruses, the innate immune system produces a mass of cytokines and chemokines. Based on GO enrichment analysis, genes expressing cytokines (IFN- $\beta, I F N-\gamma, O A S L, I F I T 5)$ and chemokines (CCL4, CCL19, CCL26, and CX3CL1) were significantly upregulated and played an antiviral role during $\mathrm{CH} 60$ infection.

Notably, expression of $I L-10$ was significantly upregulated in the livers of CH60-infected embryonated eggs. As an antiinflammatory mediator, IL-10 suppresses inflammation via various mechanisms, including reducing HLA class II expression, decreasing $\mathrm{T}$ cell secretion of IL-2, and diminishing the production of IL-1, TNF- $\alpha$, and IL- 8 by activated monocytes/ macrophages $(50,51)$. Furthermore, we found that expression of $I L-1, I L-2, T N F-\alpha$, and $I L-8$ was not significantly changed in CH60-infected livers (Table S1 in Supplementary Material); therefore, these cytokines may be suppressed by excessive expression of IL-10. Another key cytokine, IFN- $\gamma$, plays a vital role in $\mathrm{CH} 60$ infection. Unlike type I interferon, IFN- $\gamma$ participates in innate and adaptive immunity by regulating the differentiation of natural T cells (52). According to studies investigating hepatitis $\mathrm{E}$ virus, high levels of TLR3 and a robust IFN- $\gamma$ response are able to limit the disease, and hosts can recover uneventfully (53). Similar expression of TLR 3 and IFN- $\gamma$ was observed in our studies; however, the liver did not recover uneventfully, and we speculate that the virus may evade the innate immune system through an unknown mechanism.

Interestingly, we observed that expression of SOCS1 and SOCS3 was significantly upregulated in the livers of $\mathrm{CH} 60$ infected embryonated eggs; hypermethylation of SOCS3 was confirmed. These two molecules are involved in the cytokinemediated signaling pathway according to GO enrichment. Notably, a similar phenomenon was observed in multiple hepatitis models (54-56). SOCS proteins were shown to be negativefeedback regulators of cytokine signaling mediated by the JAK-STAT signaling pathway, and cytokine signaling played an important role in the differentiation, maturation, proliferation, and apoptosis of various types of cells (57). The current study revealed that SOCS1 reduces induction of the IFN signaling pathway in chicken cells and can potentiate virus replication (58). A similar study revealed that SOCS1 downregulation by miRNA 155 enhances type I IFN expression and suppresses virus replication (59). In our study, we hypothesized that the CH60 strain may utilize SOCS1 to suppress expression of IFN- $\alpha$, ultimately facilitating replication; however, further research is needed to verify this hypothesis. The JAK-STAT signaling pathway is a central communication node for the immune system (60). KEGG analysis indicated that the JAK-STAT signaling pathway played a critical role in the livers of $\mathrm{CH} 60$-infected embryonated eggs. Expression of STAT1 and STAT3, two key genes in the JAK-STAT signaling pathway, was markedly upregulated. STAT3 plays an important role in liver inflammation and cancer. The pro-inflammatory mediator IL- 6 exerts many of its functions via activation of STAT3 (61). A study investigating $\mathrm{HCV}$ revealed that $\mathrm{HCV}$ repressed the cellular antiviral response by upregulating STAT3 (62). However, interactions among SOCS, IFN, and STAT during DHAV-1 infection are not fully understood, and further research is needed.

In summary, our study is the first to utilize the RNA-Seq platform for an in-depth exploration of virus-host interactions, and we identified a number of genes that were dysregulated during $\mathrm{CH} 60$ infection and jointly analyzed these genes with pathological lesions and apoptosis. Excessive inflammatory and innate immune responses induced by the $\mathrm{CH} 60$ strain caused severe liver damage. The alternative animal model described in this study will be used for further molecular exploration of viral hepatitis and to elucidate the pathogenesis of DHAV-1.

\section{ETHICS STATEMENT}

The study was approved by the Committee of Experiment Operational Guidelines and Animal Welfare of Sichuan Agricultural University (the approved permit number is XF201418). Experiments were conducted in accordance with approved guidelines.

\section{AUTHOR CONTRIBUTIONS}

JX carried out the experiments; AC, MW, JX, and XO conceived and supervised the study; JX, QZ, and MW drafted the manuscript; JX, YM, XZ, and ML recorded gross lesions and analyzed histopathology; JX, DZ, SC, RJ, and QY analyzed the transcriptomic data and confirmed differential gene expression; and YW, SZ, YL, YY, XC, and LZ revised the manuscript. All authors reviewed the manuscript.

\section{FUNDING}

This work was supported by the National Key Research and Development Program of China (2017YFD0500800), the China Agricultural Research System (CARS-42-17), Sichuan Veterinary Medicine and Drug Innovation Group of China Agricultural Research System (CARS-SVDIP), and the Special Fund for the Key Laboratory of Animal Disease and Human Health of Sichuan Province (2016JPT0004).

\section{SUPPLEMENTARY MATERIAL}

The Supplementary Material for this article can be found online at https:/www.frontiersin.org/articles/10.3389/fimmu.2018.01845/ full\#supplementary-material. 


\section{REFERENCES}

1. Ou X, Mao S, Jiang Y, Zhang S, Ke C, Ma G, et al. Viral-host interaction in kidney reveals strategies to escape host immunity and persistently shed virus to the urine. Oncotarget (2017) 8(5):7336-49. doi:10.18632/ oncotarget. 14227

2. Qianda C, Anchun C, Mingshu W. Characteristics and function of 3D gene and its encoding protein in picornavirus. Rev Med Microbiol (2012) 23(2):18-22. doi:10.1097/MRM.0b013e328352afee

3. Cao J, Ou X, Zhu D, Ma G, Cheng A, Wang M, et al. The 2A2 protein of duck hepatitis A virus type 1 induces apoptosis in primary cell culture. Virus Genes (2016) 52(6):780-8. doi:10.1007/s11262-016-1364-4

4. Cao QD, Cheng AC, Wang MS. Bioinformatic analysis of the 3D polyprotein from duck hepatitis A virus strain $\mathrm{H}$ isolated in China. Adv Mater Res (2013) 647:396-402. doi:10.4028/www.scientific.net/AMR.647.403

5. Sun D, Chen S, Cheng A, Wang M. Roles of the picornaviral $3 \mathrm{C}$ proteinase in the viral life cycle and host cells. Viruses (2016) 8(3):82. doi:10.3390/ v8030082

6. Wen X, Cheng A, Wang M, Jia R, Zhu D, Chen S, et al. Recent advances from studies on the role of structural proteins in enterovirus infection. Future Microbiol (2015) 10(9):1529-42. doi:10.2217/fmb.15.62

7. Yang $\mathrm{X}$, Cheng $\mathrm{A}$, Wang $\mathrm{M}$, Jia $\mathrm{R}$, Sun $\mathrm{K}$, Pan $\mathrm{K}$, et al. Structures and corresponding functions of five types of picornaviral 2A proteins. Front Microbiol (2017) 8:1373. doi:10.3389/fmicb.2017.01373

8. Sun D, Wang M, Wen X, Cheng A, Jia R, Sun K, et al. Cleavage of poly(A)binding protein by duck hepatitis A virus 3C protease. Sci Rep (2017) 7(1): 16261. doi:10.1038/s41598-017-16484-1

9. Levine P, Hofstad M. Report of the poultry diagnosis laboratory at Ithaca. Report of the New York State Veterinary College at Cornell University for the Year 1944-1945; Ithaca. Geneva, New York: W. F. Humphrey Press Inc. (1946). p. 54-60.

10. Wen X, Zhu D, Cheng A, Wang M, Chen S, Jia R, et al. Molecular epidemiology of duck hepatitis a virus types 1 and 3 in China, 2010-2015. Transbound Emerg Dis (2018) 65(1):10-5. doi:10.1111/tbed.12741

11. Kamomae M, Kameyama M, Ishii J, Nabe M, Ogura Y, Iseki H, et al. An outbreak of duck hepatitis A virus type 1 infection in Japan. J Vet Med Sci (2017) 79(5):917-20. doi:10.1292/jvms.16-0646

12. Tsai H-J, Woolcock P. Viral infections of waterfow. In: Swayne DE, Glisson JR, McDougald LR, Nolan LK, Suarez DL, Nair VL, editors. Diseases of Poultry. Vol. 13. Oxford, UK: John Wiley \& Sons, Inc. (2013). p. 417-63.

13. Yugo DM, Hauck R, Shivaprasad HL, Meng XJ. Hepatitis virus infections in poultry. Avian Dis (2016) 60(3):576-88. doi:10.1637/11229070515-Review.1

14. Song C, Yu S, Duan Y, Hu Y, Qiu X, Tan L, et al. Effect of age on the pathogenesis of DHV-1 in Pekin ducks and on the innate immune responses of ducks to infection. Arch Virol (2014) 159(5):905-14. doi:10.1007/s00705013-1900-7

15. Mao S, Ou X, Zhu D, Chen S, Ma G, Wang M, et al. Development and evaluation of indirect ELISAs for the detection of $\operatorname{IgG}$, IgM and IgA1 against duck hepatitis A virus 1. J Virol Methods (2016) 237:79-85. doi:10.1016/j.jviromet.2016.08.019

16. Hu Q, Zhu D, Ma G, Cheng A, Wang M, Chen S, et al. A one-step duplex rRT-PCR assay for the simultaneous detection of duck hepatitis A virus genotypes 1 and 3. J Virol Methods (2016) 236:207-14. doi:10.1016/j.jviromet. 2016.07.011

17. Wen XJ, Cheng AC, Wang MS, Jia RY, Zhu DK, Chen S. Detection, differentiation, and VP1 sequencing of duck hepatitis A virus type 1 and type 3 by a 1-step duplex reverse-transcription PCR assay. Poult Sci (2014) 93(9):2184. doi:10.3382/ps.2014-04024

18. Shen Y, Cheng A, Wang M, Chen S, Jia R, Zhu D, et al. Development of an indirect ELISA method based on the VP3 protein of duck hepatitis A virus type 1 (DHAV-1) for dual detection of DHAV-1 and DHAV-3 antibodies. J Virol Methods (2015) 225:30-4. doi:10.1016/j.jviromet.2015.08.016

19. Anchun C, Mingshu W, Hongyi X, Dekang Z, Xinran L, Haijuen C, et al. Development and application of a reverse transcriptase polymerase chain reaction to detect Chinese isolates of duck hepatitis virus type 1. J Microbiol Methods (2009) 77(3):332-6. doi:10.1016/j.mimet.2009.02.002

20. Yang $M$, Cheng A, Wang M, Xing H. Development and application of a one-step real-time Taqman RT-PCR assay for detection of Duck hepatitis virus type1. J Virol Methods (2008) 153(1):55-60. doi:10.1016/j.jviromet. 2008.06.012

21. Ou X, Mao S, Cao J, Ma Y, Ma G, Cheng A, et al. The neglected avian hepatotropic virus induces acute and chronic hepatitis in ducks: an alternative model for hepatology. Oncotarget (2017) 8(47):81838-51. doi:10.18632/ oncotarget. 19003

22. Ou X, Mao S, Cao J, Cheng A, Wang M, Zhu D, et al. Comparative analysis of virus-host interactions caused by a virulent and an attenuated duck hepatitis A virus genotype 1. PLoS One (2017) 12(6):e0178993. doi:10.1371/journal. pone. 0178993

23. Mao S, Wang M, Ou X, Sun D, Cheng A, Zhu D, et al. Virologic and immunologic characteristics in mature ducks with acute duck hepatitis A virus 1 infection. Front Immunol (2017) 8:1574. doi:10.3389/fimmu. 2017.01574

24. Song C, Liao Y, Gao W, Yu S, Sun Y, Qiu X, et al. Virulent and attenuated strains of duck hepatitis A virus elicit discordant innate immune responses in vivo. J Gen Virol (2014) 95(12):2716-26. doi:10.1099/vir.0.070011-0

25. Kain KH, Miller JW, Jones-Paris CR, Thomason RT, Lewis JD, Bader DM, et al. The chick embryo as an expanding experimental model for cancer and cardiovascular research. Dev Dyn (2014) 243(2):216-28. doi:10.1002/ dvdy. 24093

26. Strojny B, Grodzik M, Sawosz E, Winnicka A, Kurantowicz N, Jaworski S, et al. Diamond nanoparticles modify curcumin activity: in vitro studies on cancer and normal cells and in ovo studies on chicken embryo model. PLoS One (2016) 11(10):e0164637. doi:10.1371/journal.pone.0164637

27. Beedie SL, Rore HM, Barnett $\mathrm{S}$, Chau $\mathrm{CH}$, Luo W, Greig NH, et al. In vivo screening and discovery of novel candidate thalidomide analogs in the zebrafish embryo and chicken embryo model systems. Oncotarget (2016) 7(22): 33237-45. doi:10.18632/oncotarget.8909

28. Vancamp P, Darras VM. Dissecting the role of regulators of thyroid hormone availability in early brain development: merits and potential of the chicken embryo model. Mol Cell Endocrinol (2017) 459:71-8. doi:10.1016/j. mce.2017.01.045

29. Peng M, Li S, He Q, Zhao J, Li L, Ma H. Proteomics reveals changes in hepatic proteins during chicken embryonic development: an alternative model to study human obesity. BMC Genomics (2018) 19(1):29. doi:10.1186/ s12864-017-4427-6

30. Cheng A, Liao D, Xie J, Chen X. Studies on duck viral hepatitis - pathogen isolation, identification and cultivation of attenuated viruses [J]. China J Vet Med (1993) 19(1):3-4.

31. Cardiff RD, Miller CH, Munn RJ. Manual hematoxylin and eosin staining of mouse tissue sections. Cold Spring Harb Protoc (2014) 2014(6):655-8. doi:10.1101/pdb.prot073411

32. Livak KJ, Schmittgen TD. Analysis of relative gene expression data using real-time quantitative PCR and the 2(-Delta Delta C(T)) Method. Methods (2001) 25(4):402-8. doi:10.1006/meth.2001.1262

33. Kim D, Langmead B, Salzberg SL. HISAT: a fast spliced aligner with low memory requirements. Nat Methods (2015) 12(4):357-60. doi:10.1038/nmeth.3317

34. Langmead B, Salzberg SL. Fast gapped-read alignment with Bowtie 2. Nat Methods (2012) 9(4):357-9. doi:10.1038/nmeth.1923

35. Roberts A, Pachter L. Streaming fragment assignment for real-time analysis of sequencing experiments. Nat Methods (2013) 10(1):71-3. doi:10.1038/ nmeth.2251

36. Anders S, Huber W. Differential expression of RNA-Seq data at the gene levelthe DESeq package. EMBL. Heidelberg, Germany (2012). Available from: http://gga01.med.wayne.edu/online_help/help_regionminer/DESeq.pdf

37. Kanehisa M, Araki M, Goto S, Hattori M, Hirakawa M, Itoh M, et al. KEGG for linking genomes to life and the environment. Nucleic Acids Res (2008)36(Database issue):480-4. doi:10.1093/nar/gkm882

38. Fairn GD, Grinstein S. How nascent phagosomes mature to become phagolysosomes. Trends Immunol (2012) 33(8):397-405. doi:10.1016/j.it.2012. 03.003

39. Seggewiß N, Paulmann D, Dotzauer A. Lysosomes serve as a platform for hepatitis A virus particle maturation and nonlytic release. Arch Virol (2016) 161(1):43-52. doi:10.1007/s00705-015-2634-5

40. Du H, Yang J, Bai J, Ming K, Shi J, Yao F, et al. A flavone-polysaccharide based prescription attenuates the mitochondrial dysfunction induced by duck hepatitis A virus type 1. PLoS One (2017) 12(4):e0175495. doi:10.1371/ journal.pone. 0175495 
41. Malhi H, Gores GJ, Lemasters JJ. Apoptosis and necrosis in the liver: a tale of two deaths? Hepatology (2006) 43(2 Suppl 1):S31. doi:10.1002/ hep. 21062

42. You Y, Cheng AC, Wang MS, Jia RY, Sun KF, Yang Q, et al. The suppression of apoptosis by $\alpha$-herpesvirus. Cell Death Dis (2017) 8(4):e2749. doi:10.1038/ cddis.2017.139

43. Modol T, Brice N, Ruiz de Galarreta M, Garcia Garzon A, Iraburu MJ, Martinez-Irujo JJ, et al. Fibronectin peptides as potential regulators of hepatic fibrosis through apoptosis of hepatic stellate cells. JCell Physiol (2015) 230(3):546-53. doi:10.1002/jcp.24714

44. Issa R, Williams E, Trim N, Kendall T, Arthur MJ, Reichen J, et al. Apoptosis of hepatic stellate cells: involvement in resolution of biliary fibrosis and regulation by soluble growth factors. Gut (2001) 48(4):548-57. doi:10.1136/ gut.48.4.548

45. Szabo G, Mandrekar P, Dolganiuc A. Innate immune response and hepatic inflammation. Semin Liver Dis (2007) 27(4):339-50. doi:10.1055/s-2007991511

46. Takeuchi O, Akira S. Innate immunity to virus infection. Immunol Rev (2009) 227(1):75-86. doi:10.1111/j.1600-065X.2008.00737.x

47. Brenner C, Galluzzi L, Kepp O, Kroemer G. Decoding cell death signals in liver inflammation. J Hepatol (2013) 59(3):583-94. doi:10.1016/j.jhep.2013. 03.033

48. Xie J, Wang M, Cheng A, Zhao XX, Liu M, Zhu D, et al. Cytokine storms are primarily responsible for the rapid death of ducklings infected with duck hepatitis A virus type 1. Sci Rep (2018) 8(1):6596. doi:10.1038/s41598018-24729-w

49. Faouzi S, Burckhardt BE, Hanson JC, Campe CB, Schrum LW, Rippe RA, et al. Anti-Fas induces hepatic chemokines and promotes inflammation by an NF-kappa B-independent, caspase-3-dependent pathway. J Biol Chem (2001) 276(52):49077-82. doi:10.1074/jbc.M109791200

50. Tilg H, Kaser A, Moschen AR. How to modulate inflammatory cytokines in liver diseases. Liver Int (2006) 26(9):1029-39. doi:10.1111/j.1478-3231. 2006.01339.x

51. Mosmann TR. Properties and functions of interleukin-10. Adv Immunol (1994) 56:1-26. doi:10.1016/S0065-2776(08)60449-6

52. Schoenborn JR, Wilson CB. Regulation of interferon-gamma during innate and adaptive immune responses. Adv Immunol (2007) 96:41-101. doi:10.1016/S0065-2776(07)96002-2

53. Majumdar M, Ratho RK, Chawla Y, Singh MP. Role of TLR gene expression and cytokine profiling in the immunopathogenesis of viral hepatitis E. J Clin Virol (2015) 73:8-13. doi:10.1016/j.jcv.2015.09.011
54. Fletcher SP, Chin DJ, Ji Y, Iniguez AL, Taillon B, Swinney DC, et al. Transcriptomic analysis of the woodchuck model of chronic hepatitis B. Hepatology (2012) 56(3):820-30. doi:10.1002/hep.25730

55. Um TH, Kim H, Oh BK, Kim MS, Kim KS, Jung G, et al. Aberrant CpG island hypermethylation in dysplastic nodules and early HCC of hepatitis B virusrelated human multistep hepatocarcinogenesis. J Hepatol (2011) 54(5):939-47. doi:10.1016/j.jhep.2010.08.021

56. Zhao LJ, He SF, Wang W, Ren H, Qi ZT. Interferon alpha antagonizes STAT3 and SOCS3 signaling triggered by hepatitis C virus. Cytokine (2016) 80:48-55. doi:10.1016/j.cyto.2015.08.264

57. Inagaki-Ohara K, Kondo T, Ito M, Yoshimura A. SOCS, inflammation, and cancer. JAKSTAT (2013) 2(3):e24053. doi:10.4161/jkst.24053

58. Giotis ES, Ross CS, Robey RC, Nohturfft A, Goodbourn S, Skinner MA. Constitutively elevated levels of SOCS1 suppress innate responses in DF-1 immortalised chicken fibroblast cells. Sci Rep (2017) 7(1):17485. doi:10.1038/ s41598-017-17730-2

59. Wang B, Fu M, Liu Y, Wang Y, Li X, Cao H, et al. gga-miR-155 enhances type i interferon expression and suppresses infectious burse disease virus replication via targeting SOCS1 and TANK. Front Cell Infect Microbiol (2018) 8:55. doi:10.3389/fcimb.2018.00055

60. Villarino A, Kanno Y, O'Shea J. Mechanisms and consequences of JakSTAT signaling in the immune system. Nat Immunol (2017) 18(4):374-84. doi:10.1038/ni.3691

61. He G, Karin M. NF-kappaB and STAT3 - key players in liver inflammation and cancer. Cell Res (2011) 21(1):159-68. doi:10.1038/cr.2010.183

62. Xiong Y, Zhang C, Yuan J, Zhu Y, Tan Z, Kuang X, et al. Hepatitis C virus represses the cellular antiviral response by upregulating the expression of signal transducer and activator of transcription 3 through sponging microRNA122. Mol Med Rep (2015) 11(3):1733-7. doi:10.3892/mmr.2014.2897

Conflict of Interest Statement: The authors declare that the research was conducted in the absence of any commercial or financial relationships that could be construed as a potential conflict of interest.

Copyright $\odot 2018$ Xie, Zeng, Wang, Ou, Ma, Cheng, Zhao, Liu, Zhu, Chen, Jia, Yang, $W u, Z$ hang, Liu, Yu, Zhang and Chen. This is an open-access article distributed under the terms of the Creative Commons Attribution License (CC BY). The use, distribution or reproduction in other forums is permitted, provided the original author(s) and the copyright owner(s) are credited and that the original publication in this journal is cited, in accordance with accepted academic practice. No use, distribution or reproduction is permitted which does not comply with these terms. 